\title{
Fetomaternal Outcome of Emergency Caesarean Section in a Tertiary Level Hospital
}

\author{
Sabiha Sultana ', Kamrun Nahar ${ }^{2}$, Sufia Begum Sompi ${ }^{3}$, Mst Nazmunnaher Mina ${ }^{4}$
}

\begin{abstract}
:
Background \& objective: Acute threat to the pregnant mother or their foetus may arise during the process of labor or any time after 28 weeks of gestation, when emergency caesarean section (CS) is indicated. But emergency CS is not completely safe to the mother or their foetus. The present study was undertaken to observe the foetomaternal outcome of emergency caesarean section.

Methods: This prospective observational study was conducted between January to June, 2010 in the Department of Obstetrics \& Gynaecology, Dhaka Medical College Hospital, Dhaka. All pregnant women undergoing emergency CS admitted at the the above-mentioned Hospital were the study population. The indications for emergency CS were obstructed labour, fetal distress, prolonged labour, cord prolapse, antepartum hemorrhage, antepartum eclampsia with unfavorable cervix labor with malpresentation, history of previous one caesarean section with impending scar rapture, chorioamnionitis, failed forceps/ventous etc. A total of 672 pregnant women based on predefined eligibility criteria were consecutively included in the study and fetomaternal outcome of emergency CS was evaluated.
\end{abstract}

Result: Age distribution of the patients shows that over 30\% were $25-29$ years, $26.5 \% 30-34$ years, $23.3 \%$ $20-24$ years old. About $10 \%$ were $<20$ years and another $10 \%$ were 35 or $>35$ years old. Over $20 \%$ of the mothers were short-statured $(<140 \mathrm{~cm}), 60 \%$ were nullipara, $16.5 \%$ primipara and the rest were multipara. The indications for emergency caesarean sections were previous caesarean section with complications (23.7\%) followed by foetal distress $(16.2 \%)$, antepartum hemorrhage (APH) (8.6), eclampsia (7.8\%), obstructed labor $(7.4 \%)$, severe preeclampsia, breech, prolonged labor, cephalopelvic disproportion, PROM etc. About $25 \%$ of the women were preterm, $57 \%$ were term and $18 \%$ were post-term. A total of $230(34.2 \%)$ patients developed complications following caesarean section. Wound infection (14.3\%) was the most common complication followed by wound dehiscence, puerperal pyrexia, anaemia, primary PPH, UTI, anesthesic hazarads and vesico-vaginal fistula. Sixteen (2.4\%) mother died of complications. Most common causes of death were postpartum haemorrhage $(12 \%)$, severe preeclampsia \& eclampsia $(7.1 \%)$, puerperal sepsis with septicemia (3.6\%) and cardiac arrest. About $94 \%$ of fetuses were born alive, $5 \%$ were stillborn and $1 \%$ born with congenital anomalies. Early perinatal death occurred in $10 \%$ cases who were born alive, $5.2 \%$ had neonatal jaundice and $3.3 \%$ developed septicemia. Finally, 559 (83.1\%) were discharged healthy. Of the total 113 perinatal deaths, 68 were early perinatal death.

Conclusion: The findings of the present study suggest that increased perinatal mortality was due to severe birth asphyxia following obstructed labour, placenta praevia, PROM with chorioamnionitis and eclampsia. Proper antenatal care, screening of high-risk pregnancy, timely hospital admission, neonatal resuscitation and establishment of specialized neonatal care unit can significantly reduce perinatal morbidity and mortality.

Key words: Emergency CS, foetal outcome, perinatal outcome, maternal outcome etc.

\section{Authors' information:}

'Dr. Sabiha Sultana, Assistant Professor, DGO, FCPS (Obstetrics \& Gynaecology), Delta Medical College \& Hospital, Mirpur, Dhaka.

${ }^{2}$ Dr. Kamrun Nahar, Associate prof, FCPS (Obstetrics \& Gynaecology), Shahabuddin Medical College \& Hospital, Dhaka.

${ }^{3}$ Dr Sufia Begum Sompi, Associate Professor, FCPS (Obstetrics \& Gynaecology), Delta Medical College \& Hospital, Mirpur, Dhaka.

${ }^{4}$ Dr. Mst Nazmunnaher Mina, Assistant Professor, FCPS (Obstetrics \& Gynaecology), Delta Medical College \& Hospital, Mirpur, Dhaka.

Correspondence: Dr. Sabiha Sultana, Phone: +8801711226835 E-mail:drsabihasumi@gmail.com 


\section{INTRODUCTION:}

Caesarean section (CS) is one of the most frequently practiced major obstetric operations performed either electively or as an emergency basis. WHO estimates the rate of CS, between 10 to $15 \%$ of all births in developed countries. ${ }^{1}$ When an immediate threat to the mother or the foetus arises during the process of labor or any time after 28 weeks of gestation and the indicated CS is performed within thirty minutes of decision making, it is known as emergency caesarean section. ${ }^{2}$ Like other surgery, emergency CS is not free from hazards. ${ }^{3}$ Death occur due to immediate complications like hamorrhage, shock, anesthetic hazard, infection, thromboembolism etc. Late complications include incisional hernia, intestinal obstruction due to adhesion \& bands, scar rupture in subsequent pregnancy, placental abnormality in next pregnancy are quite common. Usually, complications occur in $10 \%$ cases of emergency CS.

In the last 20 years, the rate of emergency CS has steadily increased. The underlying causes though vary from country to country, in developing countries like ours, factors are more or less related to poor socioeconomic status, illiteracy, ignorance, unawareness and unavailability of antenatal care, injudicious home handling of labor, lack of advanced scientific facilities to detect high risk pregnancies leading to undiagnosed vulnerable pregnancies. Besides these, fetal causes like fetal distress, malpresentation (breech) and maternal causes like antepartum hemorrhage, impending eclampsia, eclampsia, prolonged and obstructed labor, failure to progress labor due to cephalon-pelvic disproportion, inadequate uterine contraction, previous CS with impending scar rupture prompt the attending obstetricians to go for emergency CS on their patients. ${ }^{3}$ Fetal death occurs due to complications like prematurity, asphyxia and respiratory distress syndrome. ${ }^{3}$ For emergency CS, the pregnant women are usually checked but ASA grade is higher, often remain haemodynamically unstable, anemic or infective. These factors can contribute to high morbidity and mortality, for often women are not psychologically prepared to have caesarean delivery and that could produce fear of repeat CS in next pregnancy and puerperal psychosis. The improved safety of surgery with modern anesthetic techniques, aseptic and antiseptic precautions, availability of antibiotics, advent of blood transfusion with minimal incidence of cross-reaction and intravenous fluid have made the emergency CS more successful procedure and increasingly less hazardous. ${ }^{2}$

In emergency situation, though CS is done to avoid anticipated complications, indications should be justified and should not be practiced unethically for hospital or doctor's benefit. Dhaka Medical College Hospital is a well-reputed and well-known tertiary referral hospital where incidence of $C S$ is high (approximately 48\%). ${ }^{4}$ A large number of un-booked cases land in emergency after having mismanaged outside. Continuity, improved quality and availability of antenatal care can reduce the rate of emergency $\mathrm{CS}^{3}{ }^{3}$ The objective of the present study is to observe the foetomaternal outcome of emergency CS with particular considerations of emergency caesarean sections \& its foetomaternal complications so that unnecessary emergency CS could be avoided.

\section{METHODS:}

This prospective and observational study was conducted over a period of 6 months between January to June, 2010 in the Department of Obstetrics \& Gynaecology, Dhaka Medical College Hospital, Dhaka. All pregnant women undergoing emergency caesarean section admitted at the Hospital during the period of study were the study population. All women undergoing caesarean section for emergency indications like obstructed labour, fetal distress, prolonged labour, cord prolapse, antepartum hemorrhage, antepartum eclampsia with unfavorable cervix, labor with malpresentation, history of previous one caesarean section with impending scar rapture, chorioamnionitis, failed forceps/ventous etc. were included. Patients or attendants unwilling to give informed consent to take part in the study were excluded. However, patients with chronic infectious diseases, diabetic women, patients suffering from chronic liver disease, heart disease, renal disease, vascular 
disease etc. and women with malignant disease were excluded from the study. A total of 672 pregnant women based on above-mentioned eligibility criteria were consecutively included in the study \& fetomaternal outcome of emergency caesarean sections was evaluated. Data processing and analysis were done using SPSS (statistical package for social sciences), version 16.0. The test statistics used to analyze the data were descriptive statistics.

\section{RESULTS}

Age distribution of the patients shows that over $30 \%$ were $25-29$ years, $26.5 \% 30-34$ years, $23.3 \%$ $20-24$ years old. About $10 \%$ were $<20$ years and another $10 \%$ were 35 or $>35$ years old. Over $20 \%$ of the mothers were short-statured $(<140 \mathrm{~cm})$. Nearly $60 \%$ were nullipara, $16.5 \%$ primipara and the rest were multipara. In terms of antenatal (AN) visits, $21 \%$ received $\geq 3$ ANC visits, $32 \%<3$ visits and the rest $(47 \%)$ no antenatal visits. Approximately $90 \%$ of the study subjects received tetanus toxoid (Table I). The most common indications for emergency caesarean sections were previous caesarean section with complications (23.7\%) followed by foetal distress $(16.2 \%)$, antepartum hemorrhage (APH) due to placenta previa (8.6), eclampsia (7.8\%), obstructed labor $(7.4 \%)$, severe preeclampsia $(6.7 \%)$, breech $(6.5 \%)$, prolonged labor $(5.5 \%)$, cephalopelvic disproportion $(4.4 \%)$, PROM with or without chorioamnionitis ( $4.1 \%$ ) etc. (Table II). Gestational age distribution shows that about $25 \%$ of the women were preterm (at $<36$ weeks of gestion), $57 \%$ were term (37-40 weeks of gestation) and $18 \%$ were post-term (> 40 weeks of gestation) (Fig. 1). In 95\% cases type of anaesthesia used was spinal and caesarean section was done using lower uterine segment transverse incision (table III). Table IV shows the peroperative and post-operative complications that the patients encountered. A total of $230(34.2 \%)$ patients developed complications following caesarean section. Wound infection $(14.3 \%)$ was the most common complications followed by wound dehiscence $(8.3 \%)$, puerperal pyrexia $(7.1 \%)$, anaemia $(4.7 \%)$, primary $\mathrm{PPH}$ $(4.4 \%)$, UTI $(2.9 \%)$, anesthesic hazarads and vesico-vaginal fistula the least.

Table $\mathrm{V}$ shows the maternal deaths with their causes and timing of death. The total number of maternal death (incidence) was 16(2.4\%). Most common causes of death were postpartum haemorrhage $(12 \%)$, pulmonary oedema and renal failure resulting from severe preeclampsia \& eclampsia $(7.1 \%)$, puerperal sepsis with septicemia resulting from chorioamnionitis (3.6\%) and cardiac arrest due to anaesthetic hazards. Out of 672 births, $627(93.3 \%)$ were born alive, 38(5.6\%) were stillborn and $7(1 \%)$ born with congenital anomalies. Early perinatal death occurred in $10 \%$ cases who were born alive, $5.2 \%$ suffered from neonatal jaundice and $3.3 \%$ suffered from septicemia. Finally, 559(83.1\%) were discharged healthy (Table VI). Table VI shows perinatal outcome (in $1^{\text {st }} 7$ days) following caesarean section. There were total 113 death including 68 early perinatal death along with 38 still-born and 7 congenital anomalies. $627(93.3 \%)$ babies born alive \& total 559(83.1\%) babies were finally discharged as healthy.

TABLE I. Demographic \& obstetric characteristics of the patients Demographic \& Obstetric characteristics

Frequency

Percentage

Age (yrs.)

$<20$ 66 9.8

$20-24$

156

23.3

$25-29$

204

30.3

$30-34$

178

26.5

$\geq 35$

10.1

Height (cm)

$<140$

$\geq 140$

524

78.0

Parity

Nullipara

403

59.9

Primipara

111

16.5

Multipara

158

23.6

Received antenatal visits

$>3$ times

141

21.0

$<3$ times

215

32.0

No antenatal visit

316

47.0

Tetanus Toxoid received
600

89.3 


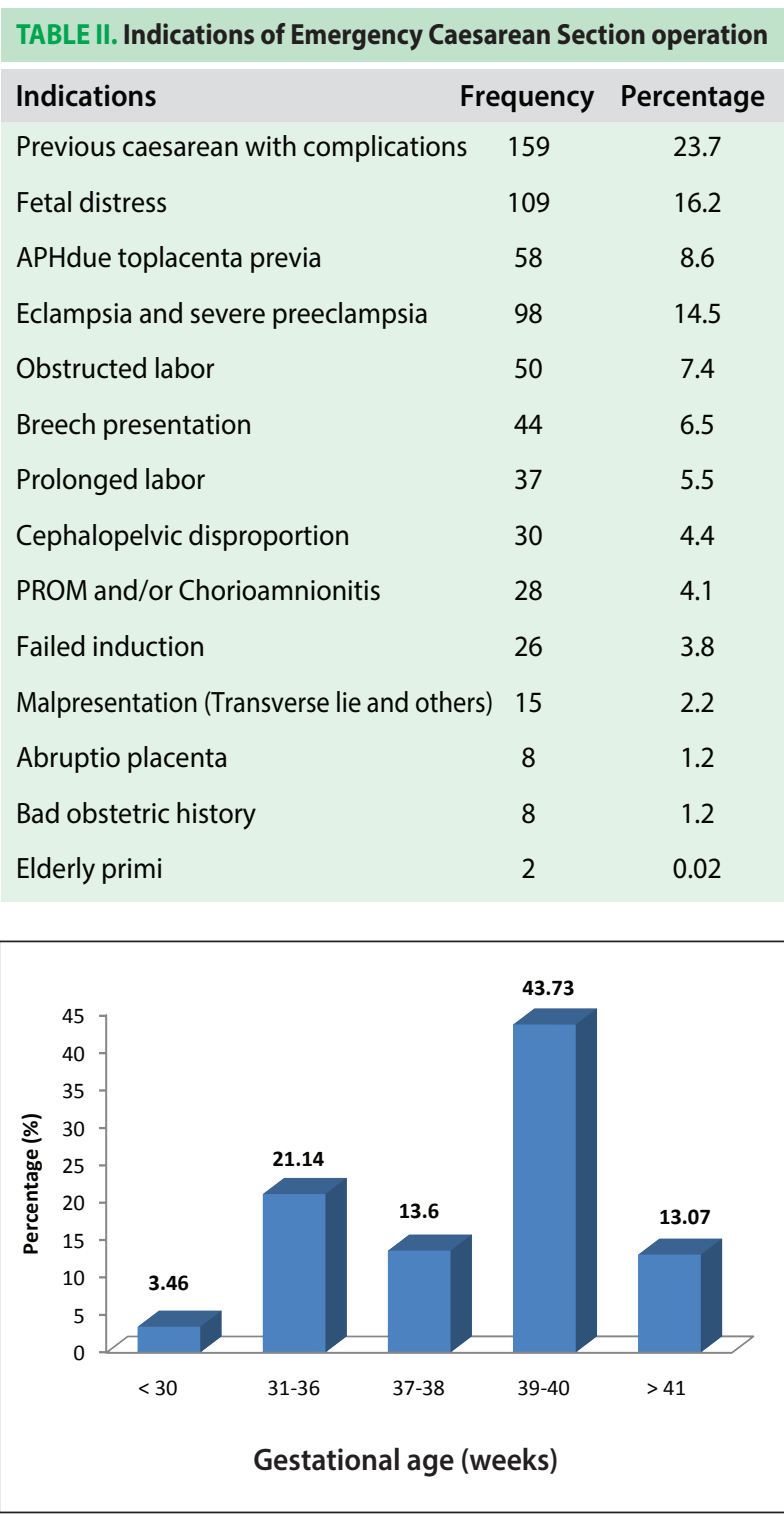

Fig.1: Gestational age of study cases at the time of Caesarean operation

TABLE III. Types of anesthesia and incision used for emergency CS

\begin{tabular}{lcc|}
$\begin{array}{l}\text { Types of anesthesia and incision } \\
\text { used for Emergency CS }\end{array}$ & Frequency & Percentage \\
\hline $\begin{array}{l}\text { Types of anesthesia } \\
\quad \text { Spinal anesthesia }\end{array}$ & 638 & 95.0 \\
$\quad \begin{array}{l}\text { General anesthesia } \\
\text { Types of uterine incision }\end{array}$ & 34 & 5.0 \\
$\begin{array}{l}\text { Lower segment (lower transverse) } \\
\text { caesarean section }\end{array}$ & 668 & 99.4 \\
caesarean section with T incision & 4 & 0.6
\end{tabular}

TABLE IV. Distribution of patients by post-operative complications $(n=672 *)$

$\begin{array}{lcc}\text { Post-operative complications } & \text { Frequency } & \text { Percentage } \\ \text { Wound infection } & 96 & 14.3 \\ \text { Wound dehiscence } & 56 & 8.3 \\ \text { Puerperal pyrexia } & 48 & 7.1 \\ \text { Anemia } & 32 & 4.7 \\ \text { Primary PPH } & 30 & 4.4 \\ \text { UTI } & 20 & 2.9 \\ \text { Anaesthetic hazards } & 4 & 0.6 \\ \text { Vesico-vaginal fistula } & 2 & 0.3\end{array}$

*Total will not correspond to $100 \%$ for multiple response.

TABLE V. Analysis of maternal death with causes $(n=672)$

\begin{tabular}{|c|c|c|c|c|c|c|c|}
\hline $\begin{array}{l}\text { Indication } \\
\text { of CIS }\end{array}$ & 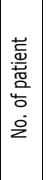 & 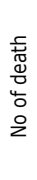 & 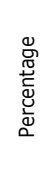 & $\begin{array}{c}\text { Causes of } \\
\text { death }\end{array}$ & $\begin{array}{l}\text { Time } \\
\text { interval } \\
\text { between } \\
\text { CIS \& } \\
\text { death } \\
\text { (hours) }\end{array}$ & $\begin{array}{l}\text { Time } \\
\text { interval } \\
\text { between } \\
\text { onset of } \\
\text { labor \& } \\
\text { Death } \\
\text { (hours) }\end{array}$ & \begin{tabular}{|l} 
Time \\
interval \\
between \\
hospitalization \\
\& death \\
(hours)
\end{tabular} \\
\hline $\begin{array}{l}\text { Sever } \\
\text { pre-eclampsia } \\
\text { \& eclampsia }\end{array}$ & 98 & 7 & 7.1 & $\begin{array}{l}\text { Pulmonary } \\
\text { odema, } \\
\text { renal failure }\end{array}$ & 24 & 36 & 30 \\
\hline $\begin{array}{l}\text { Antepartum } \\
\text { hemorrhage }\end{array}$ & 66 & 4 & 6.06 & $\begin{array}{l}\text { Post partum } \\
\text { hemorrhage } \\
\text { with shock }\end{array}$ & 16 & 24 & 18 \\
\hline $\begin{array}{l}\text { Obstructed } \\
\text { labour }\end{array}$ & 50 & 3 & 6.0 & $\begin{array}{l}\text { Post partum } \\
\text { hemorrhage } \\
\text { with shock }\end{array}$ & 8 & 26 & 10 \\
\hline Chorioamnionitis & 28 & 1 & 3.6 & $\begin{array}{l}\text { Puerperal } \\
\text { sepsis with } \\
\text { septicaemea }\end{array}$ & 36 & 48 & 72 \\
\hline Anesthetic Hazards & 4 & 1 & 25.0 & Cardiac arrest & 1 & 8 & 10 \\
\hline
\end{tabular}

TABLE VI. Perinatal outcome in the first 7days following emergency CS ( $n=672 *)$

$\begin{array}{lcc}\text { Outcome } & \text { Frequency } & \text { Percentage } \\ \text { Born alive } & 627 & 93.3 \\ \text { Still born } & 38 & 5.6 \\ \text { Congenital anomalies } & 07 & 1.0 \\ \text { Early perinatal death } & 68 & 10.1 \\ \text { Birth asphyxia } & 48 & 7.1 \\ \text { Neonatal Jaundice } & 35 & 5.2 \\ \text { Septicemia } & 22 & 3.3 \\ \text { Discharged healthy } & \mathbf{5 5 9} & \mathbf{8 3 . 1}\end{array}$

*Total will not correspond to $100 \%$ for multiple response.

\section{DISCUSSION:}

The present study was carried out to assess the fetomaternal outcome of emergency CS in Dhaka Medical College Hospital. Each patient of emergency CS was assessed according to her age, parity, 
obstetric background, indications of emergency CS, type of anesthesia used, maternal and fetal outcome. The incidence of CS is gradually increasing in developed countries as well as in developing countries. In the 1950 s $3 \%$ of birth in England were performed by CS. This figure had risen to $9 \%$ in 1980 and $12 \%$ in 1990 and rapidly reached to $21 \%$ in 2000 and $22.3 \%$ in $2001 .{ }^{5}$ The World Health Organization (WHO) have set $10-15 \%$ CS of total birth as the standard caesarean rate. ${ }^{6}$ Desmon et al stated that the limit should be put to $10 \%$ in developing countries and less than $10 \%$ for developed countries. ${ }^{7}$ Although healthy people in United States established a goal of $15 \%$ rate of CS in the year 2009, the ideal rate has not been established in the developing countries. ${ }^{8}$

The present study revealed that CS rate was over $50 \%$ among the patients admitted in Dhaka Medical College Hospital (DMCH) which compares well with that found in Nahid's study $(49.1 \%)$ in $2004 .{ }^{9}$ This rate is quite higher compared to that found in a study in India (26\%). ${ }^{10}$ In $\mathrm{DMCH}$, referral cases are transferred from other districts and peripheries as it is the tertiary care facility hospital. These emergency cases usually received trial in low resource setup either by dais, lady health workers and general practitioners causing unnecessary delay in referring the patients to tertiary level hospitals, when further trial of labor is not possible. That might be the cause of higher caesarean section in our setting.

In the present study it was found that the first indication for emergency caesarean section was previous caesarean section (23.6\%). In our country obstetricians always inclined to do caesarean in $2^{\text {nd }}$ and subsequent pregnancies if the first issue was done by caesarean section, although supervised justified trial of labor in cases of previous caesarean section may have normal delivery in many cases. The risk of scar rupture is very low, only $3 \% .{ }^{11}$ So, it appears that avoiding and reducing primary caesarean section rates should be the principal aim to reduce repeat caesarean section. The $2^{\text {nd }}$ major indication of emergency CS was fetal distress (16.2\%). The rate is $20 \%$ in Bangabandhu Sheikh Mujib Medical
University. ${ }^{12}$ In another study in UK, presumed fetal distress contributed $22 \%$ to the overall caesarean section rate. ${ }^{5}$ The diagnosis of fetal distress is often subjective without any standard clinical criteria in different health facilities. Had the decision of caesarean section due to fetal distress been guided by continuous electronic monitoring, it would have effectively reduced the caesarean section rate. Nearly $15 \%$ of emergency caesarean section were done due to eclampsia and severe preeclampsia. Nahid reported $13 \%$ of the emergency caesarean section. ${ }^{12}$ Eclamptic patients with unfavorable cervix having a history of repeated convulsions \& uncontrolled hypertension usually prompt the obstetricians to do emergency caesarean section. As caesarean section carries 8 -fold higher mortality than vaginal delivery and 12 times higher morbidity, these high-risk cases should be weighed on risk benefit ratio to reduce caesarian section rate. ${ }^{13}$

Obstructed labor is a rare phenomenon in the developed world but it is still an alarming problem in the developing world. In the present study $7.4 \%$ caesarean section was done for obstructed labor, which was lower in Nahid's study $(4 \%)^{12}$ and higher in Rajshahi and Sir Salimullah Medical College Hospitals (11 and $10 \%$ respectively). ${ }^{9}$ Nwosu and colleagues ${ }^{14}$ from Nigeria, however reported a staggeringly higher rate of caesarean sections (42\%) for obstructed labor. Placenta praevia comprised $8.6 \%$ of emergency caesarean section. Consistent with this finding, Shamshed et al showed $8 \%$ caesarean section due to placenta praevia. ${ }^{15}$ Good antenatal care and early diagnosis of placenta praevia by USG can reduce emergency caesarean section to some extent. PROM with chorioamnionitis contributed to $4.1 \%$ cases of emergency CS. Poor hygienic concept, lack of knowledge about genitourinary infections, trial at home by untrained birth attendants and repeated per vaginal examination seems to be associated with this incidence.

The incidence of maternal morbidity following emergency caesarean section was $34.2 \%$. Of them, wound infection was $14.3 \%$ and wound dehiscence $8.3 \%$. Jalil and $\mathrm{Khan}^{16}$ showed similar 
incidence of morbidity in emergency CS (37.5\%). A study in Glasgow found that there was considerable postoperative morbidity associated with CS, particularly if the operation was carried out as an emergency procedure. ${ }^{17}$ Sharply contrasting with these findings, William et al $^{18}$ reported wound infection in only $1.54 \%$ cases and UTI in $4.6 \%$ cases after CS at Sioux valley Hospital, South Dakota. Complications like wound infection, febrile morbidity and endometritis develop more after emergency CS in case of premature rupture of membranes, prolong duration of labor with repeated per vaginal examination, while puerperal pyrexia with septicemia is more common after CS in case of obstructed and prolonged labor. In the present study, incidence of maternal death was $2.4 \%$, the causes of death were post-partum haemorrhage $(12 \%)$ severe preeclampsia \& eclampsia leading to pulmonary oedema and/or renal failure $(7.1 \%)$ and chorioamnionitis $(3.6 \%)$. Nilufer in a similar study showed maternal mortality to be $2 \%$ and the causes of death were eclampsia and sepsis. ${ }^{19}$ The mortality rate in emergency CS largely depends on the indication of operation, type of anaesthesia, efficiency of anesthesiologist, associated medical or pregnancy related complications.

In terms of perinatal outcome, severe birth asphyxia was $7.1 \%$ with admission to Neonatal Intensive Care Unit needed $1.3 \%$, followed by still born $5.2 \%$, early neonatal death $10.1 \%$, congenital anomaly $1 \%$ of cases. All these perinatal complications were alarmingly high in Tedesse et al study in Ethopia with stillbirths being $4.8 \%$ and neonatal death $4.7 \% .^{20}$ Dey and Hatai at Calcata also found neonatal complications higher $(21.8 \%)$ in emergency caesarean section..$^{21}$

The findings of the present study suggest that increased perinatal mortality was due to severe birth asphyxia following obstructed labour, placenta praevia, PROM with chorioamnionitis and eclampsia. Proper antenatal care, screening of high-risk pregnancy, timely hospital admission, neonatal resuscitation and establishment of specialized neonatal care unit can significantly reduce perinatal morbidity and mortality.

\section{REFERENCES:}

1. Royston E, Armstrong D. Preventing Maternal Deaths, World Health Organization, Geneva 1989:9-10.

2. Dewhurst's text book of Obstetrics \& Gynecology, Keith Edmonds (Editor), $7^{\text {th }}$ edition;233-234. ISBN: 978-0470-75333-0

3. Answers.com, the world leading Q \& A site by Bethany Thivierge, Medical Encyclopedia : Caesarean section, 2008.

4. Statistics of Dhaka Medical College hospital, 2008.

5. Caesarean Sections. Postnote 2002;(184):1-4). Available at:https://www.parliament.uk/documents/post/ pn184.pdf

6. WHO Statement on Caesarean Section Rates. Department of Reproductive Health and Research, Geneva, Switzerland, 2015. Available at: http://apps.who.int/iris/bitstream/handle/10665/161442/WHO_RHR_15. 02 eng.pdf?sequence $=1$

7. Desmon R, Patel NB, Thiery M. Implications of increasing rate of caesarean section. Prog Obstet Gynaecol 1987;6:175-93.

8. J-Neelson,Caeserian section web site, 2004, available at www.nlss, nih, gov/medicine plus, html.

9. Paul NC. A study in complication of caesarean section in SOMCH. Dhaka (Dissertation), BCPS. 2004.

10. Bhasin SK, Rajoura OP, Sharma AK, Metha M, Gupta N, Kumar S, Joshi ID. A High Prevalence of Caesarean Section in East Delhi. Indian Journal of Community Medicine 2007;32(3):222-224.

11. Spong CY, Landon MB, Gilbert S, Rouse DJ, Leveno KJ, Varner $\mathrm{MW}$, et. al. Risk of uterine rupture and adverse perinatal outcome at term after cesarean delivery. Obstet Gynecol 2007;110(4):801-7.

12. Nahid S. A clinical Study of 100 cases on indication of caesarean section in BSMMU. (Dissertation), BCPS. 2005.

13. Sreevidya S, Sathiyasekaran BW. High caesarean rates in Madras (India): a population-based cross sectional study. BJOG 2003;110(2):106-11.

14. Nwosu C, Agumor K, Aboyeji AP, Ijaiya MA.Outcome of Caesarean Section in a Sub-Urban Secondary Health Care Facility in Nigeria. Nigerian Medical Practitioner 2004;46(4):77-79. 
15. Shamshad. Factors leading to increased caesarean section rate. Gomal J Med Sci 2008;6(1):1-5.

16. Jalil R, Khan A. Review of caesarean section at Lyary General hospital. Pakisthan Journal of Surgery 2007; 23(4):291-95.

17. Parrott $\mathrm{T}$, Evans $\mathrm{AJ}$, Lowes $\mathrm{A}$, Dennis $\mathrm{KJ}$. Infection following cesarean section. J Hosp Infect 1989;13: 349-54.

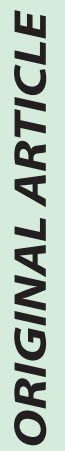

18. Williams PS, Warwick R, Dyson M, Bannister $H L$, editors. Gray's Anatomy, 37th ed. Edinburgh: Churchill Livingstone, 1995.
19. Sultana, Nilufar. A clinical Study of caesarean section (Dissertation), Dhaka, BCPS. 1997.

20. Tadesse E, Adane M, Abiyou M. Caesarean Section deliveries at Tikur Anbessa Teaching Hospital, Ethiopia. East Afr Med J 1999;73(9):619-22.

21. Dey N, Hatai SK. A study of caesarean section cases with special references to maternal and neonatal outcome. J India Med Assoc 1992;90(6):149- 51. 